\title{
A CENA MUSICAL "BLUES” DE FORTALEZA 1989-1992: OS PRIMEIROS MOMENTOS DO BLUES PAI D'ÉGUA
}

\author{
Leopoldo de Macedo Barbosa ${ }^{1}$
}

Recebido em: 07/04/2020

Aprovado em: 04/06/2020

\begin{abstract}
Resumo: Este texto tem o objetivo de analisar os primeiros momentos da chamada cena musical "blues" em Fortaleza, entre os anos de 1989 e 1992. Nesse espaço de atuação marcado por uma produção musical e que posteriormente, na segunda metade da década de 1990, seria simbolicamente denominada de Blues Pai D'Égua, evidenciamos sujeitos os quais contribuíam para o desenvolvimento e efetivação do "blues" em Fortaleza. Quanto aos seus primeiros anos, a cena musical gradualmente se integrava e se destacava no contexto musical fortalezense por meio do crescimento do público, aumento de shows ou surgimento de artistas que participavam de diferentes shows em lugares como a barraca Kafua (na região litorânea da cidade, especificamente na Praia do Futuro). Ainda sobre essa cena musical identificamos sua ligação com as movimentações vinculadas ao "rock ' $n$ ' roll”", porque a presença de agentes que produziam esses dois gêneros musicais significava atuação para essas produções. Interligados, eles (por meio dos sujeitos envolvidos) construíam uma Fortaleza jovem e inquieta. Para fomentar teoricamente o texto apresentamos o conceito de cena musical; já em termos metodológicos evidenciamos principalmente os materiais hemerográficos com base em reportagens dos jornais $O$ Povo e Diário do Nordeste (jornais de grande circulação no Ceará). Palavras-chave: "Blues"; "Rock 'n' roll”; Fortaleza; Juventude; Cena musical.
\end{abstract}

\section{LA ESCENA MUSICAL "BLUES" DE FORTALEZA 1989-1992: LOS PRIMEROS MOMENTOS DEL BLUES PAI D'ÉGUA}

Resumen: Este texto tiene como objetivo analizar los primeros momentos de la escena musical denominada "blues" en Fortaleza, entre los años 1989 y 1992. En este espacio de acción marcado por una producción musical y que luego, en la segunda mitad de la década de 1990, sería simbólicamente llamado Blues Pai D'Égua, destacamos sujetos que contribuyeron al desarrollo y realización del "blues" en Fortaleza. En cuanto a sus primeros años, la escena musical gradualmente se fue integrando y destacando en el contexto musical de Fortaleza a

\footnotetext{
${ }^{1}$ Doutorando pelo Programa de Pós-Graduação em História e Espaços da Universidade Federal do Grande do Norte e professor de História da rede pública de ensino, Prefeitura Municipal de Pacatuba-Ceará. E-mail: leopoldombarbosa@gmail.com. ORCID: https://orcid.org/0000-0002-4368-7274. Este artigo é parte da dissertação intitulada Fique escutando que eu vou aqui cantando meu Blues Pai D'Égua: a produção "blues" de Fortaleza entre relações e encontros 1989-1999. Seu objetivo é a analisar a produção "blues" na década de 1990 por intermédio dos integrantes dos quatro principais grupos atuantes e responsáveis pela consolidação dessa produção na segunda metade da referida década; Sub Blues, Gang da Cidade, Matutaia e Trakajá Blues Experiment. Os integrantes: Venícius Aurélio Borges Teixeira (Kazane), Carlinhos Perdigão e Carlos Fredrik (exintegrantes da Sub Blues); Marcelo Justa e Laerte Duarte (ex-integrantes da Gang da Cidade); Kenny Beaumont (ex-Matutaia) e Elisafan Rodrigues (ex-Trakajá Blues Experiment).
} 
través del crecimiento de público, un aumento de espectáculos o la aparición de artistas que participaban en diferentes espectáculos en lugares como la carpa Kafua (en la región costera de la ciudad)., concretamente en Praia do Futuro). Aún con respecto a esta escena musical, identificamos su conexión con los movimientos vinculados al "rock' $\mathrm{n}$ 'roll", porque la presencia de agentes que produjeron estos dos géneros musicales significó actuar para estas producciones. Interconectados, ellos (a través de los sujetos involucrados) construyeron una Fortaleza joven e inquieta. Para promover teóricamente el texto, presentamos el concepto de escena musical; En términos metodológicos, destacamos principalmente los materiales hemerográficos basados en reportajes de los periódicos O Povo y Diário do Nordeste (periódicos de gran circulación en Ceará).

Palabras clave: "Blues"; "Rock 'n' roll”; Fortaleza; Juventud; Escena musical.

\title{
THE MUSICAL SCENE “BLUES" OF FORTALEZA 1989-1992: THE FIRST MOMENTS OF BLUES PAI D'ÉGUA
}

\begin{abstract}
This text aims to analyze the first moments of the so-called "blues" music scene in Fortaleza, between the years 1989 and 1992. In this space of action marked by a musical production and later, in the second half of the 1990s, seriously symbolically called Blues Pai $D^{\prime} E$ gua, we highlight the following contributions to the development and implementation of the "blues" in Fortaleza. As for its early years, a music scene gradually integrated and highlighted in a musical context strengthened through public growth, increased shows or the emergence of artists who participate in different shows in places like a Kafua tent (in the coastal region of the city), specifically at Praia do Futuro). Still on this music scene, it identifies its connection with movements linked to "rock and roll", because the presence of agents that produce these two musical genres means acting for these productions. Interconnected, they (through the subjects involved) build a young and restless Fortaleza. To theoretically foster text, present the concept of a music scene; in methodological terms of evidence, mainly the hemerographic materials based on reports from the newspapers $O$ Povo and Diário do Nordeste (newspapers of great circulation in Ceará).
\end{abstract}

Keywords: "Blues"; "Rock 'n' roll”; Fortaleza; Youth; Music scene.

A relação entre produção musical e cidade é um escopo que constantemente revela para os pesquisadores a capacidade dos sujeitos de darem novas significações para o espaço citadino. Quando encontramos música produzida no âmbito urbano, evidenciamos práticas as quais promovem protagonismos quanto à atuação de distintos indivíduos. Como o fazer música não é algo fechado, ela extrapola fronteiras, promove laços, reverbera sentimentos ou transforma frequentemente de forma física ou simbólica a cidade.

Por intermédio dessa ampliação do fazer música, ou seja, dessa ideia de que a produção musical desenvolve um campo de influência com base na atuação de artistas e em suas relações com o espaço citadino (como a manutenção de espaços musicais, a promoção "de shows" ou como a reunião de um determinado público), evidenciamos estudiosos utilizando o conceito de 
cena para compreender um espaço simbólico relacionado a um determinado gênero musical e capaz de desenvolver mudanças na forma de se relacionar com a cidade.

O termo cena já era utilizado por jornalistas especialmente a partir da segunda metade do século XX (FONSECA, 2011). Além disso, a menção é sugestiva. Pensar em um palco simbólico em que atores (os sujeitos envolvidos) desenvolvem suas encenações (suas movimentações ou seus interesses musicais), a fim de promover não só um gênero musical específico, mas também suas próprias carreiras. Posteriormente, nomes como Will Straw propôs uma abordagem conceitual para o termo. Para Straw (1991, p. 373) cena é: "that cultural space in which a range of musical practices coexist, interacting with each other within a variety of processes of differentiation, and according to widely varying trajectories of change and crossfertilization" $"$.

Já Garson (2009, p. 7-8), reforçando o conceito de cena musical (relacionando o conceito com a questão da música), destaca que:

o termo marca sua entrada em território acadêmico a fim de dar conta da pluralidade de sentidos e a lógica dos cruzamentos que as expressões musicais estabelecem entre si, mais centrais que a tentativa de delimitar sua circulação e reivindicar a força de suas raízes e mitos de origem. De importância essencial no conceito é a constatação de que nas atividades mundanas de se escutar música, conversar e dançar se revelam os códigos e sentidos ocultos nas cenas musicais.

Cena musical trata de delimitar simbolicamente fronteiras as quais circunscrevem as práticas musicais de um determinado grupo na cidade. Pensar espaço enquanto algo praticado e construído por meio da música significa pensar a forma como um lugar (um bairro ou um local musical) é ressignificado, quando um público o adota para seus encontros; o modo como músicos constituem sociabilidades por intermédio de um gênero musical ou ainda a maneira como esse espaço simbólico tem a capacidade de dar voz a esses agentes.

De forma dinâmica cena musical se perpetua na cidade, se reinventa ou ordinariamente, remetendo às práticas ordinárias estudadas por Certeau (1998) subverte uma aparente ordem com base em suas limitações. Portanto, o interesse de conceito de cena se encontra na ideia de se pensar produção musical dentro de um espaço de atuação simbólico e interferente na cidade.

Quanto à nossa pesquisa, a cena musical analisada se refere à produção "blues". Gênero 3 afro-estadunidense, o "blues" influenciou diferentes manifestações musicais no país como o

\footnotetext{
2 "É aquele espaço cultural em que uma série de práticas musicais coexistem, interagindo entre si dentro de uma variedade de processos de diferenciação e de acordo com trajetórias amplamente variadas de mudança e fertilização cruzada (tradução nossa) ".

${ }^{3}$ Em nossas discussões com base na análise de Correa (2019), utilizamos a categoria gênero para definir práticas, características e delimitações vinculadas a uma determinada manifestação musical.
} 
“jazz” e, portanto, representa um dos pilares quando falamos de música nos Estados Unidos. Além disso, o gênero musical conserva durante toda sua trajetória, o legado de luta, resistência e valorização da cultura afro-estadunidense com base em diferentes canções. No Brasil (como veremos posteriormente), o "blues" se consolidou por meio de jovens os quais já produziam “rock ' $n$ ' roll” e passaram a encontrar no gênero musical, uma nova referência.

Historicamente em Fortaleza, nosso foco de estudo, direcionamos nossa perspectiva para o intervalo, entre o final dos anos 1980 e o início da década de 1990, no qual representou um momento importante para a produção "blues" fortalezense, caracterizado pelo desenvolvimento de uma cena musical. Nesse período um espaço simbólico vinculado a essa produção passava a ocupar o cenário musical local e a atuar de forma significativa. Essas movimentações que desde do final da década de 1970 aconteciam no contexto musical local, agora, no recorte temporal delimitado, passavam a ganhar destaque com o aparecimento de artistas, diferentes apresentações e um desenvolvimento de um público. Simbolicamente, nós utilizamos uma expressão utilizada por $K_{a z a n e}{ }^{4}$ na composição Nova Vitrola; umas das diferentes canções presentes no álbum Blues Ceará ${ }^{5}$. O chamado Blues Pai D'Égua ${ }^{6}$ tornou referência para aquilo que era produzido na época.

Além de entendermos a produção "blues" fortalezense por meio da construção de uma cena musical, evidenciamos uma discussão que se sustenta principalmente nos depoimentos dos artistas atuantes, nos materiais hemerográficos, em outras fontes (como as virtuais) e nas escassas referências bibliográficas relacionadas ao objeto. Nesse texto quanto aos depoimentos, utilizamos a entrevista de Kazane para fomentar o marco inicial simbólico da cena musical “blues", o ano de 1989. Já os periódicos (matérias dos jornais O Povo e Diário do Nordeste) nos auxiliam na compreensão das movimentações não só desse espaço simbólico, mas também

\footnotetext{
${ }^{4}$ Venícius Aurélio Borges Teixeira, o Kazane, é um dos principais nomes da cena musical "blues" fortalezense. Conhecido artista plástico local, começou efetivamente sua carreira musical ainda na década de 1980. Dos projetos nos quais ele participou destacamos a Skala e a Sub Urb Banda (grupos que falaremos posteriormente) como também a Sub Blues, banda formada por Kazane na década de 1990.

${ }^{5}$ O álbum Blues Ceará, lançado em 1998, reúne 16 canções dos quatro grupos já citados anteriormente: Sub Blues, Gang da Cidade, Matutaia e Trakajá Blues Experiment. O registro é um marco não só para produção "blues" local (porque foi o primeiro material fonográfico do gênero lançado no Ceará), mas também para a cena musical, pois representou a consolidação dela em Fortaleza. Além disso, o álbum levou essas 4 bandas a se transformarem nas principais referências para esse espaço simbólico no período.

${ }^{6}$ Cabe lembrar que o intuito do texto não se refere a analisar especificamente aspectos da produção Blues Pai $D^{\prime}$ Égua, e sim, o contexto dos primeiros momentos de sua cena musical. No entanto, é interessante apresenta-la mesmo que de forma breve. O Blues Pai D'Égua é um modo de produzir "blues", relacionado à construção de um espaço simbólico (a partir do final dos anos 1980) e identificado especialmente nos trabalhos musicais das já citadas Sub Blues, Gang da Cidade, Matutaia e Trakajá Blues Experiment. Por ressaltar uma das principais características dessa produção, referente à aproximação do "blues" com elementos da cultura local (por meio das trajetórias de seus integrantes), o termo pai d'égua, uma expressão local, reforça a aproximação. Além disso, o Blues Pai D'Égua só se tornou referência pela participação desses grupos no álbum Blues Ceará. Para saber mais sobre o Blues Pai D'Égua ver Barbosa (2018).
} 
do cenário musical fortalezense como um todo (principalmente as atividades ligadas ao "rock 'n' roll"). Por sua vez, utilizamos um documento diverso (uma referência encontrada em um blog), a fim de substanciar o artigo, aumentando seu rol metodológico. Já, a bibliografia se embasa no estudo de Barbosa (2012) ${ }^{7}$.

Por fim, para a discussão ora proposta procuramos especificamente analisar os primeiros anos da cena musical "blues" entre 1989 e 1992, a fim de compreender as diferentes movimentações as quais contribuíam para o início do desenvolvimento desse espaço simbólico. Portanto, o texto tem o objetivo de analisar os primeiros momentos da cena musical "blues" em Fortaleza.

\section{O início da cena musical "blues" de Fortaleza}

Tendo o intuito de estudar o processo inicial de desenvolvimento da cena musical "blues" de "Fortaleza" optamos por fazer nossa abordagem em dois períodos: 1989, ano simbólico referente ao início do desenvolvimento da cena musical "blues", porque identificamos principalmente as atividades da Sub Urb Banda, projeto em que Kazane participou e utilizou para desenvolver suas propostas artísticas posteriormente incorporadas na Sub Blues ${ }^{8} ; 1990$ a 1992, período marcado pelo surgimento de artistas que produziam "blues"; por um incremento de eventos os quais inseriam o gênero musical como também por um aumento de público com base na presença de uma atração nacional a qual detalharemos posteriormente, o primeiro show da banda carioca Blues Etílicos ocorrido em 1992.

Optando por uma análise em dois períodos, o processo de desenvolvimento da cena musical "blues" aparece de forma mais precisa, porque evidenciamos as principais movimentações de cada momento problematizando-as, a fim de ressaltar o papel delas para o desenvolvimento e para a existência de um espaço simbólico ligado ao "blues" em Fortaleza.

\footnotetext{
${ }^{7}$ A monografia intitulada Sentimentos do blues: a cena e $(m)$ personagens na cidade de Fortaleza 1988-1998 se destaca por ser um dos primeiros estudos que identificou a existência de uma cena musical "blues" em Fortaleza. Além disso, a pesquisa procura analisar os instrumentos utilizados pelos músicos envolvidos para a manutenção desse espaço simbólico.

${ }^{8}$ Apresentamos as considerações para explicar a ausência nesse texto dos grupos analisados na pesquisa. A $S u b$ Blues e a Trakajá Blues Experiment foram formadas em 1993. A Matutaia (a única banda não local) chegou do Rio de Janeiro em 1996. Já a Gang da Cidade, formada em 1992, aparece nas discussões com outro nome, Sangue da Cidade, até adotar a primeira nomenclatura definitivamente a partir de 1993.
} 
1989

De acordo com os materiais documentais analisados, mostramos 1989 como marco simbólico inicial, pois detectamos primeiramente a atuação da Sub Urb Banda. Com base em sua formação ressaltamos três características: não foi um projeto totalmente de Kazane, teve o “rock 'n' roll” como principal proposta sonora e seu tempo de atividade foi breve, ou seja, não encontramos evidências para além desse ano. Por meio desses aspectos, o grupo aparentemente aparece distante do desenvolvimento da cena musical "blues", no entanto, o modo como Kazane participou dela a insere nas discussões sobre a formação do espaço simbólico.

Kazane em 1989 ainda mantinha contato com a banda Scala, um grupo também de "rock 'n' roll” com bastante circulação no cenário musical fortalezense ${ }^{9}$. Com a banda, ele conseguia inserir sua proposta artística $^{10}$, contudo, não realizava sua atividade de forma efetiva por causa de outras propostas existentes. Ainda nesse ano, integrantes da Skala, incluindo Kazane, resolveram formar a Sub Urb Banda que tendo maior participação dele possuía maior afinidade com seus interesses artísticos. No depoimento a seguir, identificamos mais detalhes dessa experiência:

É exatamente aí é Sub blues, Sub Urb Banda. A Sub Urb Banda já foi exatamente depois da Scala, inclusive com elementos da banda Scala Entendeu? [...] Como eu te disse [a] Sub Urb Banda saiu da Scala, porque na Scala já tinha três projetos [musicais] juntos sabe? Tinha o [do] César Leitão, o [do] Djalma Barbosa e o [do] Kazane, então, [...] eu peguei o meu [projeto] ]...] e fui pra Sub Urb Banda [com] [...] a ideia de lançar isso [...], mas que também ficou ali para acolá, [...] porque não tinha a linguagem minha [era] um outro cantor sabe? [...] Isso só funcionou quando eu fui cantar [...] aí pronto! (Entrevista, Venícius Aurélio Borges Teixeira "Kazane", Fortaleza, 26/08/2015).

O depoimento do artista é relevante para construir o contexto relacionado ao desenvolvimento da cena musical "blues" em Fortaleza. Ter um objeto carente de referências bibliográficas e, consequentemente, respaldado pelas fontes encontradas, nos leva a utilizar os depoimentos (como o de Kazane) e outros documentos como os materiais hemerográficos para preencher as lacunas detectadas como também substanciar com evidências a narrativa proposta por esse estudo. Com base na memória dos sujeitos pesquisados e, por consequência, no uso da História oral (atentando-se às diferentes peculiaridades detectadas quanto a suas

\footnotetext{
${ }^{9}$ A Scala, durante a segunda metade da década de 1980 (seu período de atividade), atuou de forma significativa e teve diferentes formações. Por sua vez, destacamos as participações mais longevas de Kazane (percussionista), do baixista César Leitão e do guitarrista Djalma Barbosa (futuro companheiro de Kazane na Sub Urb Banda).

${ }^{10}$ A proposta de Kazane remetia a produzir um "blues" agregando elementos sonoros vinculados ao "rock 'n' roll" e com letras principalmente ligadas à cidade de Fortaleza. Essas características também compõem a produção Blues Pai D'Égua.
} 
rememorações), podemos apresentar as perspectivas dos envolvidos; imprescindíveis para uma análise histórica mais plural.

A primeira evidência mostrada é a forma como Kazane mencionou o nome de seu antigo grupo. Além de Sub Urb Banda, ele utilizou Sub blues, referindo-se a seu projeto posterior e denotando lacunas em sua rememoração acerca da experiência abordada. Por outro lado, analisando a informação com base em uma perspectiva diferente, podemos indicar uma ideia de continuidade, porque Kazane, expondo tanto a primeira quanto a segunda banda, sugere implicitamente elementos comuns entre as duas. A aproximação é reforçada, quando ele inicialmente mencionou que levou seu conceito artístico à Sub Urb Banda, no entanto, ela também não chegou a ter sua efetiva assinatura. Só posteriormente, a partir do momento em que Kazane assumiu a função de vocalista, ocorreu a fomentação de sua proposta artística por meio da criação de um novo grupo.

Por intermédio do raciocínio podemos entender que a $S u b U r b$ Banda foi uma espécie de pré-projeto da Sub Blues, pois ela serviu como uma espécie de laboratório artístico para Kazane. Mesmo o artista não tendo um espaço efetivo na banda, ele chegou a experimentar, ou seja, a desenvolver sua proposta; o resultado não foi o esperado, porque a Sub Urb Banda não tinha a rubrica de Kazane, no entanto, o artista conseguiu a experiência necessária para montar seu projeto seguinte.

Ademais, reforçamos também sua importância, porque a atuação de Kazane na Sub Urb Banda revela ainda no final da década de 1980 elementos da produção Blues Pai D'Égua. Portanto, quando direcionamos nossas observações para o ano de 1989, identificamos características dessa proposta artística ainda pontuais e em formação, contudo, características que inserem a Sub Urb Banda no processo de desenvolvimento não só da cena musical "blues", mas também da produção Blues Pai D'Égua.

Além da participação de Kazane na Sub Urb Banda, uma reportagem de 23/02/1989 do jornal $O$ Povo sobre a produção "blues" em Fortaleza fornece outros aspectos para ressaltar o ano de 1989 como marco simbólico:

\section{BLUES}

Essa onda vem pegando

No início, foram os negros africanos entoando longos lamentos, em suas canções de trabalho, nas plantações de algodão, na nova terra: América. A mistura do grito primal às work-songs, mais os acordes dos hinos religiosos e a estrutura das baladas fez, segundo o crítico Roberto Muggiati, in "O que é o jazz" (Ed. Brasiliense) a fundir tudo e criar o blues. Este gênero se aperfeiçoou no final do século 19 e além de ser um dos mais importantes elementos do jazz conseguiu marcar toda a música popular deste século. Hoje no Brasil uma verdadeira onda de blues já toma conta do sul do país, a ponto da imprensa dizer que 1989 será o ano do Blues. 
É em São Paulo que a febre vem atacando com mais força, embora o Rio não fique muito atrás. Como sempre acontece, a tendência é isso repercutir em outros centros urbanos e em Fortaleza isso já se faz sentir. Algumas casas noturnas já incluem jazz e por extensão o blues em suas programações, inclusive ao vivo (BLUES..., 1989, p. 1).

Por meio da matéria anterior inicialmente salientamos sua atenção à série de eventos vinculados ao "blues" principalmente no eixo São Paulo/ Rio de Janeiro. O ano de 1989 foi marcado por lançamentos de materiais fonográficos e pela realização de festivais, transformando o final dos anos 1980 como marco simbólico inicial para a consolidação ${ }^{11}$ da produção do gênero musical no Brasil. Barbosa (2012, p. 39-40) reforça esse contexto:

Em 1985, [...] iniciou o processo de formação de uma das mais conhecidas bandas de "blues" do Brasil, a Blues Etílicos. Em 1989 a referida banda e o músico André Christovam gravaram respectivamente os álbuns Água Mineral e Mandinga, ambos pela gravadora Eldorado. Os dois trabalhos musicais foram mencionados como colaboradores da inserção do gênero no Brasil. Se mencionamos de um lado O Festival Internacional de blues de Ribeirão Preto como contribuinte, os respectivos álbuns também começaram a mudar o curso da história.

[...]

Assim, o ano de 1989 [...] representou, simbolicamente, o ano que iniciava o blues no Brasil.

Em relação à produção "blues” de Fortaleza, a reportagem apresentada mencionou seu desenvolvimento de forma imprecisa, mostrando uma movimentação vinculada aos artistas os quais produziam tanto esse gênero musical quanto o "jazz". Como já apresentamos anteriormente, quando identificamos Kazane com uma proposta artística baseada no "rock ' $\mathrm{n}$ ' roll" (utilizada futuramente em seu projeto de "blues") e como veremos posteriormente (no próximo tópico), o desenvolvimento da cena musical "blues" fortalezense esteve muito mais próxima das movimentações relacionadas ao "rock ' $\mathrm{n}$ ' roll” com base em artistas que produziam os dois gêneros musicais ${ }^{12}$. Provavelmente por causa da pouca visibilidade deles no período, o autor da reportagem não conseguiu captar e se aprofundar nessas movimentações.

Com base nas poucas informações divulgadas pela matéria anterior, percebemos uma distância entre a realidade da produção "blues" presente em Fortaleza e a pauta proposta por

\footnotetext{
${ }^{11}$ Cabe reiterar o entendimento do termo consolidação já apresentado anteriormente no texto. A menção significa uma presença definitiva, ou seja, uma espécie de chancela simbólica quanto à produção de um gênero musical. A nível nacional o "blues" se consolidava, no final dos anos 1980, porque era notório a presença de artistas, festivais ou materiais fonográficos vinculados ao gênero musical. Já a nível local, essa notoriedade, ou seja, a chancela simbólica da produção "blues" fortalezense só viria com o primeiro grande evento, o lançamento do já citado álbum Blues Ceará na segunda metade da década de 1990.

${ }^{12}$ Lembrando que a aproximação não foi uma situação exclusiva do contexto musical local. Muggiati (1995, p. 191) reforça a proximidade no âmbito nacional: "só em meados dos anos 70 começaram a brotar por aqui as primeiras bandas exclusivamente de blues, em sua maioria formadas por jovens brancos de classe média saturados do rock e que não conseguiam encontrar na MPB uma identificação para seus anseios e seu estilo de vida".
} 
ela, revelando uma certa fragilidade do material documental analisado. Se ela se torna frágil quanto à abordagem das movimentações do gênero musical, por outro lado, se torna relevante, porque contribui para um entendimento da presença de álbuns de "blues" no Brasil e em Fortaleza. A reportagem selecionada mostrou que em 1989 o contexto nacional não só estava em ascensão por causa dos eventos ocorridos como festivais, mas também por causa da inserção no mercado fonográfico brasileiro de coletâneas, reunindo registros sonoros de diferentes artistas do gênero musical:

\section{BLUES PARA TODOS}

A imprensa paulista se vale do grande número de shows, programas de rádio, lançamentos de discos tudo à base de blues para justificar a ideia de 89 ser o ano do dito gênero musical. A gravadora WEA anuncia o lançamento de um pacote de nada menos que 12 Lps de blues, na coleção "The Legacy of the Blues" (BLUES..., 1989, p. 1).

Diferentemente das poucas informações apresentadas sobre as movimentações ligadas ao "blues" em Fortaleza, ela foi precisa quando abordou a inserção de materiais fonográficos no Brasil. Essa presença estava associada à iniciativa de gravadoras (como a Warner Music, a citada no outro trecho da matéria mostrada anteriormente) que tendo os direitos autorais de diferentes gravações de "blues" aproveitavam o mercado em alta para trazer álbuns especialmente coletâneas. Com base na iniciativa feita por elas procuramos saber se as capitais brasileiras eram contempladas por suas decisões ou se suas propostas se restringiam a regiões como o Sul ou o Sudeste. A resposta aparece por meio de um indício encontrado na nota do jornal $O$ Povo de 15/02/1989 acerca da disponibilidade de um LP (coletânea) do músico $B$. $B$. King:

\section{KING OF THE BLUES BB \\ King/MCA records}

A venda na Francinet Discos por Ncz\$ 8,40 O rei do "Blues" está de volta e como sempre cada vez melhor, para os aficionados da música negra americana, este LP não pode passar em branco (KING..., 1989, p. 4).

Esse anúncio pode indicar tanto que, mesmo sem o impacto encontrado em capitais como São Paulo e Rio de Janeiro, o crescimento da divulgação do "blues" no país reverberava em Fortaleza quanto à existência de materiais fonográficos e consequentemente a circulação de conteúdos de "blues" na transição dos anos 1980 para a década de 1990. A nota, apesar de não confirmar um consumo consistente de "blues", sugere uma relativa presença do gênero musical em Fortaleza no período. Por isso, se a nível nacional o "blues" se consolidava, a nível local dava indícios de uma crescente circulação.

Para reforçar que conteúdos vinculados ao "blues" estavam em evidência no período, mencionamos também as programações televisivas em canais como a Rede Globo ou a antiga 
Manchete, dedicando parte de suas grades para a apresentação de "shows" do gênero musical. Na matéria do jornal $O$ Povo de 03/08/1989 identificamos a divulgação de um programa dedicado ao músico B. B. King:

O mestre do blues hoje na Manchete

Um especial com Riley B. Jing, considerado por críticos especializados como o "rei do blues", é o que está programado para hoje na Rede Manchete. Apelidado de B. B. há mais de quarenta anos, quando começou a se apresentar em rádio, na emissora Kwem de Menphis, nos EUA. B. B; a propósito, é a abreviação de Blues Boy, título que o acompanha até hoje e faz jus ao bluesman mais importante da atualidade (O MESTRE..., 1989, p. 4).

Com base nos materiais documentais apresentados evidenciamos que a cena musical ligada ao "blues" em 1989 se baseava no processo inicial de circulação e experimentação sonora. Por um lado, identificamos a reverberação na cidade da repercussão do "blues" produzido e consumido a nível nacional (principalmente no Sudeste), por outro, encontramos Kazane o qual, mesmo não produzindo exatamente o gênero musical na época, experimentava uma proposta artística que utilizaria posteriormente e se transformaria em referência para a cena musical "blues" fortalezense. Por isso, retomando a iniciativa de artista de experimentar sua proposta artística ainda com a Sub Urb Banda bem como a indicação da existência de materiais fonográficos e a circulação de conteúdos de "blues" em Fortaleza, percebemos o ano de 1989 como marco simbólico inicial da cena musical vinculada a esse gênero, pois se a cena não estava efetivamente delimitada, ela já dava sinais de uma existência.

\section{0 a 1992}

Existência que se transformou em delimitação e constância, porque analisando o ano de 1990 e consequentemente o início da década de 1990 identificamos um novo percurso para a produção "blues" fortalezense. Esse caminho ocorreu principalmente, pois encontramos inicialmente o retorno das atividades da banda Material.

A Material era a antiga banda de Laerte Duarte ${ }^{13}$ na década de 1980 e não só produzia “blues”, mas também “rock 'n’ roll”. Ela encerrou suas atividades aproximadamente entre 1987

\footnotetext{
${ }^{13}$ Laerte Duarte é outro representante da cena musical "blues" fortalezense. Iniciou sua carreira musical na década de 1980, atuando com destaque na banda Material. Nesse período uma das principais apresentações da banda ocorreu no Circo Voador, quando esse espaço musical do Rio de Janeiro também foi montado por meio de seus produtores em Fortaleza em 1986. Com base na repercussão da Material, Laerte Duarte e demais integrantes tentaram na capital carioca prosseguir com uma carreira musical sem o resultado esperado. Posteriormente, já em Fortaleza o artista retomou suas atividades com a Material; em 1992 reformulou o grupo, redenominando-o Sangue da Cidade (abordado posteriormente), até definitivamente renomea-lo com os demais integrantes Gang da Cidade em 1993.
} 
e 1989, depois de alguns de seus integrantes decidirem viajar para o Rio de Janeiro (incluindo Laerte Duarte). Eles reativaram a Material no início dos anos 1990 com base na reportagem a seguir:

London London encerra férias com Banda Material

O London London encerra hoje sua programação de férias com a apresentação da Banda Material. O "show" é resultante de uma vasta pesquisa feita pelo grupo e abrange ritmos primitivos e progressivos que passam pelo blues, rock, funk, reggae, bossa e outros ritmos que vão além das composições de seus integrantes [...].

A Banda Material estreou em 1986, no Circo Voador com sucesso de crítica e público. Seguiram-se outras apresentações em bares da cidade [...]. Na segunda fase [...], o grupo se dissolveu [...]. Após dois anos, retornam e reestruturam a banda [...] (LONDON..., 1990, p. 4).

A reportagem do jornal O Povo data de 28/01/1990, um indício de que Laerte Duarte retomou seu grupo pouco tempo depois de retornar de viagem. Como base na matéria apresentada, observamos que ela complementa por meio de uma informação lacunas encontradas, pois em alguns momentos os personagens estudados não conseguiram contornar totalmente seus eventos passados principalmente questões mais precisas. Como estamos abordando representações do passado permeadas por intencionalidades, incongruências, lembranças ou esquecimentos, os materiais hemerográficos são importantes para embasar documentalmente. À medida que aparecem, as reportagens revelam diferentes aspectos da cena musical "blues". Os artistas atuantes, os eventos, a relevância desse espaço simbólico no cenário musical local ou ainda sua dinâmica quanto a sua atuação, enfim, diferentes questões são elucidadas por meio dos materiais hemerográficos.

Outro aspecto na reportagem anterior se refere à menção dos diferentes gêneros musicais que influenciavam a Material. Esse aspecto reforça uma característica encontrada tanto no período entre 1990 e 1992 quanto no decorrer da década referente à presença de artistas produzindo "blues", mas não de forma exclusiva. Evidenciando o grupo produzindo também o “rock 'n' roll”, identificamos um indício de uma cena musical que se desenvolvia e mantinha uma proximidade com as movimentações ligadas a esse gênero por meio de seus integrantes.

Ademais, era comum a presença de sujeitos envolvidos com a produção não só de "rock 'n' roll', mas também de outros gêneros musicais. Para saber mais dessas incorporações analisamos o repertório de uma apresentação, um dos elementos que compõe a produção musical. Os repertórios dos envolvidos com a cena musical "blues" encontrados pela pesquisa geralmente eram compostos por "covers" (interpretações de canções lançadas por outros artistas) e composições autorais. Essa forma de elaboração se mostra interessante, porque nos 
ajuda a identificar as propostas sonoras de diferentes artistas como a da Material baseada no "blues", "rock 'n' roll”, "funk" ou no "reggae".

Um caráter identificado na cena musical "blues", a dinamicidade dos agentes integrantes no decorrer desse período, é algo que se torna inerente a distintos espaços simbólicos, quando evidenciamos sujeitos se envolvendo com produções de diferentes gêneros musicais ${ }^{14}$.

Ainda sobre a Material evidenciamos sua participação em um festival ocorrido em Fortaleza com base em outra reportagem, também do jornal O Povo, datada de 05/05/1991:

Hoje é dia de rock

A finalíssima do Primeiro Festival de Rock da AABB

Os roqueiros da cidade têm hoje um encontro marcado na praia da AABB onde acontece a finalíssima do primeiro festival AABB'ROCK. Depois de duas eliminatórias acontecidas respectivamente nos dias 20 e 27 de abril, foram escolhidas dez bandas entre as vinte inscritas, por uma comissão julgadora que incluía jornalistas, produtores, DJ's, críticos de música e até um ator de teatro.

MATERIAL

Laerte (vocal), Armando (bateria), Jomar (Guitarra), Bebeto Portela (baixo), participação especial das PERUAS: Rimena, Betty Blue e Gláucia Porto nos backings vocals.

Desde 86 na estrada, a banda MATERIAL faz uma mistura de blues e rock. "Despretensiosa e teatral" é a linha que adotaram para classificar "ROCK ADOLESCENTE" (LAERTE) na finalíssima. Detalhe: as PERUAS são as únicas mulheres no festival (HOJE É DIA..., 1991, p. 6).

Identificar as movimentações da Material demonstra que a dinamicidade do grupo também se baseava na participação de diferentes eventos. Assim, participar de apresentações individuais, coletivas ou mostras competitivas garantia visibilidade e presença do grupo no cenário musical fortalezense.

Outro grupo de destaque durante os primeiros momentos da cena musical "blues" fortalezense foi a Companhia Blue ${ }^{15}$. Entre 1990 e 1992, a banda mantinha uma consistente atuação no cenário musical local. Analisando informações sobre a Companhia Blue, podemos obtê-las na reportagem de 30/05/1991 do jornal Diário do Nordeste:

Rock e blues na praia

Uma banda que trabalha principalmente com a influência do "blues" americano, dentro de sua releitura feita por diversos grupos americanos e

\footnotetext{
${ }^{14} \mathrm{O}$ envolvimento dos agentes participantes da cena musical "blues" com produções de diferentes gêneros musicais foi uma característica presente nesse período. Mesmo com a consolidação do espaço simbólico, os personagens estudados continuaram essa dinamicidade. Posteriormente, a partir dos anos 2000, a maioria dos futuros integrantes praticamente passariam a atuar de forma exclusiva na produção do "blues".

${ }^{15}$ Conforme os indícios encontrados, o período de atividade da Companhia Blue ocorreu entre 1990 e 1994 (ano de encerramento do grupo). Portanto, a banda atuou efetivamente no crescimento da cena musical "blues, no entanto, não participou da consolidação desse espaço simbólico na segunda metade da década de 1990. Além disso, destacamos como participantes da Companhia Blue: Fernando Catatau (guitarra), Júnior (vocal e guitarra), Hamílton (bateria) e Régis Damasceno (baixo).
} 
ingleses dos anos 60. Assim trabalha o grupo cearense "Companhia blue" que se apresenta, hoje na Barraca Subindo ao Céu, na Praia do Futuro [...].

Com apenas oito meses de formação, o Companhia Blue se destacou pela sua participação no Festival de Rock promovido no London London [...] e já fez algumas apresentações que chamaram atenção dos fãs de "blues" e rock [...]. O grupo toca composições próprias [...] e versões para clássicos do "blues" e rock de várias bandas e artistas como B.B. King, Jimi Hendrix, Eric Clapton [...] (ROCK..., 1991, p. 3).

Com base na matéria observamos que a Companhia Blue surgiu com uma produção vinculada ao "blues" e ao "rock 'n' roll”, aspecto reforçado pelos artistas citados por seus integrantes como influências musicais, representados por nomes ligados aos dois gêneros como Jimi Hendrix ou Eric Clapton. Assim, a proposta sonora da Companhia Blue apresenta o grupo como um dos artistas que fluía entre as cenas musicais "blues" e "rock 'n' roll" de Fortaleza. Mais uma evidência que reforça a proximidade entre essas duas produções, ou seja, um indício o qual as movimentações vinculadas ao "rock 'n' roll” contribuíam para o desenvolvimento do espaço simbólico ligado ao "blues".

Além disso, com base em outro aspecto presente na matéria anterior, percebemos que enquanto a Material retomava sua atividade logo no início de 1990, provavelmente em setembro desse ano a banda Companhia Blue iniciava sua trajetória, pois a reportagem datada de maio de 1991 mostrou que ela estava com oito meses de atividade. Em outra matéria datada de 14/02/1991, encontramos mais indícios da participação da Companhia Blue na cena musical "blues" fortalezense:

As bandas driblam a crise

A união de bandas para driblar as dificuldades está cada vez mais frequente no cenário musical de Fortaleza. Desta vez são as bandas Companhia Blue e Poesia de Concreto que fazem show juntas. No próximo domingo, elas integram a programação do projeto 'Pôr do sol na Kafua', da barraca Kafua Praia do Futuro - a partir da 16h30min. O projeto bem sido um espaço aberto para as bandas de rock cearenses, tendo iniciado há quase dois meses (AS BANDAS..., 1991, p. 6).

Novamente apresentamos uma reportagem que reforça a dinamicidade das atuações desses grupos. Atuando em uma cena musical em ascensão e enfrentando dificuldades diversas como a busca por "shows", a Companhia Blue se juntava a outro grupo, a Poesia de Concreto, a fim de garantir mais oportunidades. Esse aspecto reforça o espaço de atuação da cena "blues" musical, mesmo não sendo um espaço simbólico grande ou consolidado, era visível seu desenvolvimento gradual no cenário musical fortalezense.

As informações referentes à Material e à Companhia Blue são elementos importantes para a compreensão do desenvolvimento da cena musical "blues", porque identificamos dois artistas atuando periodicamente em Fortaleza. Salientando esse indício, detectamos 
movimentações vinculadas ao "blues" mais relevantes diferentemente das ocorridas em épocas anteriores. Se em 1989, as evidências nos direcionam para sinais de uma existência, conforme mencionamos anteriormente, no início dos anos 1990, nossa perspectiva detecta uma maior presença com base em uma produção mais consistente, ou seja, um contínuo o qual mostra a manutenção de um espaço simbólico vinculado ao "blues".

$\mathrm{Na}$ observação das fronteiras que eram construídas por meio do desenvolvimento da cena musical "blues", evidenciamos as atividades de artistas enformando um espaço simbólico na cidade. Nos gostos em comum, nas sociabilidades as quais designam sujeitos se encontrando para suas experiências musicais ou na aparente cotidianidade do entretenimento o qual escamoteia a persistência de artistas, quanto ao desenvolvimento de suas carreiras como também de uma produção musical, encontramos indivíduos e suas ações, ou seja, a cena enquanto espaço simbólico construído e praticado denota um estar assim como um agir no inquieto, plural e disputado lugar chamado cidade:

cenas não são simplesmente o nome que damos aos meios informais de organização do lazer, [...] as cenas surgem a partir dos excessos de sociabilidade que rodeiam a buscam de interesses, ou que fomenta a inovação e a experimentação contínuas na vida cultural das cidades [...]. As cenas [...] podem ser consideradas, mais formalmente, como unidades de cultura urbana (como subculturas ou mundos de arte), como uma das estruturas do evento por meio das quais a vida cultural adquire a sua solidez. As cenas são uma das infraestruturas da cidade para troca, interação e instrução (STRAW, 2013, p. $13)$.

Para fomentar o caráter de desenvolvimento e de presença da cena musical "blues", evidenciamos as participações da Material e da Companhia Blue no festival Rock Pra Valer ${ }^{16}$. O evento é importante, porque, além de suas atuações, a vencedora foi justamente uma artista que produzia os dois gêneros musicais, já citados anteriormente, Leninha Andrade ${ }^{17}$, com base na reportagem de 15/01/1991 do jornal O Povo:

Rock in Fortaleza carece de inovações

Enquanto o Rock In Rio II não chega, as bandas de rock cearenses já fizeram a sua parte. Que o diga a cantora Leninha. Acompanhada da Contrabanda, ela venceu o Festival Rock Pra Valer, promovido pelo London London e CocaCola, Graças a sua voz rasgada, no melhor estilo Janis Joplin, Leninha abiscoitou o $1^{\circ}$. Lugar.

Injustiça? Até que não. O problema é que quaisquer que fossem os músicos a acompanhar Leninha, ainda assim ela teria grandes chances de ganhar, já que consegue se sobrepor à banda. Muitos ficaram meio ensimesmados: uma cantora de blues vencer um festival de rock? Ora, Joplin não fazia "amor" com 25 mil pessoas em suas apresentações?

\footnotetext{
${ }^{16}$ O Festival Rock Pra Valer foi uma promoção da Coca-Cola para divulgar o Rock In Rio II ocorrido no mesmo ano.

${ }^{17}$ Infelizmente não encontramos outras informações sobre a trajetória artística dessa cantora nos anos posteriores.
} 
E a banda Material Blues - em atitudes de irreverência ou "rebeldia juvenil" - acabou cantando música que não a programada. Conquistaram o quinto lugar.

Apesar de tudo, o nível do festival pode ser considerado muito bom. Daqui para a frente o negócio é as bandas não deixarem a peteca cair (no caso, quando acabar a febre do Rock In Rio), e tentar invadir outros espaços lembrem-se que a lambada faleceu... (JORGE, 1991, p. 5).

Ressaltamos inicialmente a circulação da Material e da Companhia Blue, porque suas participações no festival Rock Pra Valer reforçam a atuação da produção "blues" fortalezense e consequentemente o desenvolvimento de uma cena musical. Ademais, por meio da vencedora Leninha Andrade identificamos mais um artista produzindo esse gênero musical.

Ainda em relação à matéria apresentamos o comentário do autor sobre a vitória de Leninha Andrade, porque ele mencionou a possibilidade de algumas pessoas questionarem o fato de uma artista de "blues" vencer um festival de "rock 'n' roll". Observando seu comentário metaforicamente, poderíamos imaginar esse gênero musical começando a incomodar outras cenas musicais já consolidadas em Fortaleza, por outro lado, abordando a citação dele de forma analítica salientamos sua reflexão para reforçar o desenvolvimento da cena musical "blues".

Além disso, a reflexão proposta pela matéria (bem como a discussão apresentada nesse tópico) substancia novamente nossa hipótese, ou seja, entender que a cena musical "blues" fortalezense se desenvolveu por intermédio das movimentações ligadas ao "rock ' $\mathrm{n}$ ' roll". Porque revelar artistas como Leninha Andrade, a Material ou a Companhia Blue significa identificar os agentes que fluíam entre esses dois gêneros e, por consequência, evidenciar o ponto de aproximação o qual garantia ao mesmo tempo a manutenção da cena musical "rock 'n' roll" e o desenvolvimento da cena musical "blues".

Ainda em 1991 identificamos a atuação da Blues \& $\mathrm{Cia}^{18}$, outro artista envolvido com a cena musical "blues" com base nos materiais documentais estudados. Na reportagem do Diário do Nordeste de 15/07/1991 encontramos uma divulgação de uma apresentação desse grupo:

Bar das Seis ${ }^{19}$ encerra programação cultural

Atração [..] no encerramento da programação cultural da gestão do Sindicato dos Bancários, no Bar das Seis [...]. Às 23h30min toca o grupo Blues \& Cia que faz um repertório baseado no "blues" dos negros norte-americanos e dos astros consagrados do rock [...].

A banda Blues \& Cia integrados por músicos amadores que se uniram pela força do "Blues". Na lista de influência do grupo estão nomes do blues

\footnotetext{
${ }^{18}$ Formavam a Blues \& Cia nessa época Gilvan (guitarra), Luiz (baixo), Wellington (bateria), Júnior (teclados) e Chiquinho (gaita). Ressaltamos que depois de 1991 não encontramos nos materiais documentais estudados outras atividades dela.

${ }^{19}$ Não encontramos maiores informações sobre esse local.
} 
americano, como BB King, Buddy Guy e [...] das bandas nacionais, eles citam especialmente o quinteto carioca Blues Etílicos (BAR..., 1991, p. 4).

Novamente encontramos um artista que produzia os gêneros musicais já citados por intermédio das influências da Blues \& Cia apresentadas pela reportagem. Ademais, salientamos com base nessa matéria o caráter amador de seus integrantes (ou seja, sujeitos os quais não viviam exclusivamente da música), uma característica identificada na cena musical "blues", mas que se torna inerente a distintos espaços simbólicos, conforme mencionamos anteriormente, quando evidenciamos sujeitos se envolvendo com as produções de diferentes gêneros musicais.

Ainda sobre as características que essas cenas musicais, especificamente a do "blues" e a do "rock 'n' roll", comungavam ressaltamos a da cartografia afetiva. Rodrigues (2011) para reforçar as subjetividades vinculadas à aproximação entre sujeitos e cidade constrói o conceito de cartografia afetiva. Esse aporte teórico remete aos lugares apropriados e praticados nos quais se criam vínculos e afetividades.

Majoritariamente elas por meio de seus integrantes se apropriavam dos mesmos lugares. Como exemplos citamos as barracas de praia, pois para além de representantes do lazer da Praia do Futuro (região litorânea leste de Fortaleza) a partir dos anos 1980, esses locais significavam espaços para a arte, assim, reservavam oportunidade também para a produção "blues". $\mathrm{Na}$ reportagem do jornal O Povo de 15/12/1991 identificamos a divulgação de um "show" da banda Companhia Blue na barraca Kafua:

Blues à beira-mar

Barraca Kafua chama banda Companhia Blue para animar o pôr-do-sol de Domingo

A Barraca Kafua agita mais uma para o pôr-do-sol do dia 15. A partir das 16h30min deste domingo, a banda Companhia Blue solta os acordes em músicas que vem com as assinaturas de Santana, Erick Clapton às baladas de Cazuza e Barão Vermelho, interpretadas pela voz e guitarra de Júnior Boquinha, o baixo de Régis Damasceno, a guitarra de Fernando Catatau e a bateria de Hamilton.

O evento soma-se à mostra fotográfica ocorrida há duas semanas, na intenção de programar atrações diferentes para os finais de tarde à beira-mar. A barraca Kafua fica na Praia do Futuro, próxima ao hotel Praia Sol (BLUES À BEIRAMAR, 1991, p. 4).

Podemos reforçar a atuação da Companhia Blue nessas barracas por meio de uma lembrança de Fernando Catatau (que, conforme mencionamos anteriormente, foi um integrante 
do grupo) encontrada em um texto no "blog" intitulado Trabalho Sujo ${ }^{20}$. A evidência fomenta a utilização dos chamados documentais virtuais:

[...] Eu lembro que tinham muitos lugares pequenos em que a gente se apresentava, a maioria na Praia do Futuro, como o Kafua, onde moravam uns hippies, o Loco Maluco, o Biruta quando ainda era uma barraca pequena e legal, o Igrejinha [...]. A maioria fechou por causa da violência, os que ainda existem são tapados com madeira e paga-se pra entrar. Antes era de graça mesmo.

Por intermédio das informações da reportagem anterior e da lembrança de Fernando Catatau encontramos a cena musical "blues" também por meio da juventude transformando e ocupando Fortaleza, pois era nesse espaço simbólico que aos poucos se desenvolvia uma rede ativa conectando diferentes agentes e os encaminhando para uma apropriação dessa cidade. Sobre o papel da juventude em relação ao espaço citadino, Sá (in GOMES I.; JANOTTI JR., 2011, p. 155-156) mostra que diferentes grupos juvenis

[...] apropriam-se de pedaços das cidades para suas práticas, criando circuitos concretos marcados pelos rastros do agrupamento em movimento, enfatizando simultaneamente a efervescência das cidades enquanto espaços sociais vívidos e produtivos.

Com base na apropriação de Fortaleza por meio da atuação de diferentes artistas, analisamos o ano de 1992 para evidenciar determinadas transições, pois bandas como a Companhia Blue continuaram com suas atividades, no entanto, grupos como a Material passaram por reformulações. Mencionamos que Laerte Duarte passou a atuar no período após 1991 com a recém-formada Sangue da Cidade. No período, após a experiência com a Material, o artista se reuniu como novos músicos ${ }^{21}$, assim, ele a partir de 1992, participaria de um novo projeto. Na reportagem do jornal O Povo de 03/05/1992 identificamos uma divulgação de uma apresentação da Sangue da Cidade novamente na barraca Kafua:

Diário de Bordo

Woodstock seja aqui! No velho Aurélio, Cafua quer dizer antro, cova, esconderijo, cafundó. Em Fortaleza, Kafua se escreve com K, point obrigatório dos últimos herdeiros da contracultura cabeça-chata. E hoje à tardinha [...] será o lançamento do livro "Diário de Bordo", as experiências astrais do baiano Ricardo [...] um dos frequentadores históricos da Kafua. Animando a festa, um show da banda Sangue da Cidade [e] no cenário, o dublê de músico e artista plástico Kazane pinta e completa o astral (DIÁRIO..., 1992, p. 5).

Essa reportagem reforça uma cena musical "blues" a qual se renovava e se desenvolvia no início da década de 1990. No entanto, salientamos que sua renovação e seu desenvolvimento

${ }^{20}$ Disponível em: http://trabalhosujo.com.br/a-historia-oral-de-uma-fortaleza-interior/. Acesso: 29/07/2017 às $21 \mathrm{~h} 05 \mathrm{~min}$.

${ }^{21}$ Apresentamos Celso Antuni (guitarra), Marco Aurélio (baixo) e Júnior (gaita). 
não se resumiam às atividades de diferentes artistas ou a uma presença de materiais fonográficos em Fortaleza. Com base no desenvolvimento desse espaço simbólico, o público também progredia, assim, começava a florescer o interesse de produtores locais em "shows" de artistas de renome nacional. Diante do quadro positivo, eles trouxeram em 1992 a Blues Etílicos.

O primeiro "show" da Blues Etílicos em Fortaleza aconteceu em outubro de 1992 no espaço artístico chamado Anima Café Concerto. A matéria do jornal Diário do Nordeste de 28/10/1992 apresentou informações da apresentação:

Blues Etílicos faz show hoje em Fortaleza

Se o 'blues' no Brasil tem algum prestígio, o quinteto carioca Blues Etílicos tem grande responsabilidade no aval que o público brasileiro dá ao gênero nascido entre os negros americanos. Com cinco anos e meio de carreira, quatro discos lançados, é a primeira que o grupo faz uma excursão pelos estados do Nordeste do País. O Blues etílicos faz apresentação única hoje, a partir das 22 horas no Anima Café Concerto - bairro Joaquim Távora.

"Está excursão está nos mostrando no ápice de nossa carreira. A gente chegou a um entrosamento perfeito", fala o guitarrista Otávio Rocha. Para o baixista Cláudio Bedran, este entrosamento se deve justamente ao fato da banda ter a mesma formação desde o início da carreira. O Blues Etílicos é integrado por Cláudio, Otávio (guitarra-slide), Greg Wilson (voz e guitarra), Flávio Guimarães (voz e gaita) e Gil Eduardo (bateria) (BLUES..., 1992, p. 1).

O Ânima Café Concerto se localizava no centro de Fortaleza especificamente na avenida Visconde do Rio Branco, além disso, por meio da atuação dele essa região principalmente entre 1992 e 1995 (período de seu funcionamento) se transformou em outra referência na cartografia afetiva da cena musical "blues". Sobre o "show" apresentado, sua realização significava uma forma de divulgação da produção artística da Blues Etílicos pelo Nordeste, pois algumas cidades ainda não tinham recebido seus "shows".

Com base na apresentação da Blues Etílicos no final de 1992 podemos ressaltar também que sua apresentação encerrava o segundo período entre 1990 e 1992. Esse momento marcado pelo desenvolvimento da cena musical "blues" fortalezense, reforçando uma rede cada vez mais relevante que unia produtores, artistas ou o crescente público.

\section{Considerações finais}

O primeiro ponto acerca das discussões propostas no artigo se refere ao conceito de cena musical. Pensar produção com base na aproximação de sujeitos com um determinado gênero musical e na constituição de um espaço simbólico significa ampliar as possibilidades teóricas quanto à relação entre arte e cidade. Produzir artisticamente influencia o espaço citadino. Fazer música, conforme mencionamos anteriormente, não significa apenas entretenimento; pelo 
contrário, identificar artistas atuando nas cenas musicais representa novas leituras ou novos percursos para a cidade.

Em Fortaleza, a dinamicidade da cena musical "blues" por meio de seus integrantes favorecia seu desenvolvimento. Entre 1989 e 1992 revelava aos poucos na cidade uma produção que posteriormente, na segunda metade da década de 1990, seria chamada de Blues Pai D'Égua. Essa menção evidencia a aproximação e a interferência do "blues" produzido com a cidade de Fortaleza como também a representatividade desse modo de fazer "blues" no cenário musical local. Apresentações eram realizadas como os "shows" da Material e da Companhia Blue; espaços ou regiões citadinas eram apropriados como o Ânima Café Concerto e a Praia do Futuro (que passaram a receber shows de "blues"), respectivamente; sociabilidades se efetivavam, quando os diferentes envolvidos se encontravam nessas apresentações ou ainda experiências se concretizavam por meio desses sujeitos os quais descobriam por meio do "blues" suas subjetividades. Mostra-se interessante identificar esses indivíduos pluralizando a cidade com base em seus fazeres musicais.

Ademais, por meio do "show" da Blues Etílicos identificamos o caráter global das cenas musicais, pois encontramos espaços simbólicos de diferentes cidades se territorializando e desterritorializando por intermédio das alianças ou dos contatos de seus integrantes. Nesse caso, a aproximação das produções "blues” fortalezense e carioca (JANOTTI JR., 2014).

O segundo ponto evidencia a aproximação entre as cenas musicais "blues" e "rock ' $n$ ' roll". Com base nos indícios apresentados identificamos artistas que produziam os dois gêneros musicais, portanto, facilitando a presença e a circulação deles. Enquanto o "rock 'n' roll” era divulgado em diferentes eventos como festivais ou nos próprios trabalhos musicais de diferentes artistas, o "blues" palmilhava as oportunidades e em um primeiro momento, de forma paralela, conseguia de forma gradual promover sua perenidade por meio de um desenvolvimento de uma cena musical. Para exemplificar identificamos os artistas Companhia Blue e a Material (posteriormente Sangue da Cidade); grupos que fluíam entre esses dois gêneros musicais e responsáveis pela manutenção do espaço simbólico ligado ao "blues".

Finalmente o terceiro ponto está pautado na construção simbólica de uma Fortaleza pautada na juventude e na produção musical. Nesse outro espaço citadino se construíam experiências que transformavam esses jovens em protagonistas quanto à ocupação e interferência na cidade. Na Fortaleza juvenil, inquieta e atuante emergiam sujeitos os quais procuravam enaltecer suas vozes e promover uma cidade mais polifônica como também mais participativa. 


\section{Referências bibliográficas}

\section{Materiais hemerográficos}

AS BANDAS driblam a crise. Diário do Nordeste, Fortaleza, 14 fev. 1992, Caderno 3, p. 4.

BAR Da Seis encerra programação cultural. Diário do Nordeste, Fortaleza, 15 jul. 1991, Caderno 3, p. 4.

BLUES à beira-mar. O Povo, Fortaleza, 15 dez. 1991, Vida \& Arte, p. 4.

BLUES: essa onda vem pegando. O Povo, Fortaleza, 23 fev. 1989, Vida \& Arte, p. 1.

BLUES Etílicos faz show hoje em Fortaleza. Diário do Nordeste, Fortaleza, 28 out. 1992, Caderno 3, p. 1.

DIÁRIO de Bordo. O Povo, Fortaleza, 03 mai. 1992, Vida \& Arte, p. 5.

HOJE é dia de rock. O Povo, Fortaleza, 05 mai. 1991, Vida \& Arte, p. 6.

JORGE, Ricardo. Rock in Fortaleza carece de inovações. O Povo, Fortaleza, 15 jan. 1991, Vida \& Arte, p. 5.

KING of The Blues - BB King. O Povo, Fortaleza, 15 fev. 1989, Vida \& Arte, p. 5.

LONDON London encerra férias com banda Material. O Povo, Fortaleza 28 jan. 1990, Vida \& Arte, p. 4

O MESTRE do blues hoje na Manchete. O Povo, Fortaleza, 03 ago. 1989, Vida \& Arte, p. 4.

ROCK e blues na praia. Diário do Nordeste, Fortaleza, 30 mai. 1991, Caderno 3, p. 3.

\section{Fontes orais}

TEIXEIRA, Venícius Aurélio Borges. Venícius Aurélio Borges Teixeira "Kazane": depoimento [ago/set. 2015]. Entrevistador: Leopoldo de Macedo. Fortaleza: 2015. 1 arquivo sonoro.

\section{Páginas da internet}

MATIAS, Alexandre. A história oral de uma Fortaleza interior. Disponível em: http://trabalhosujo.com.br/a-historia-oral-de-uma-fortaleza-interior/. Acesso: 29/07/2017 às $21 \mathrm{~h} 05 \mathrm{~min}$. 


\section{Bibliografia}

BARBOSA, Leopoldo de Macedo. Sentimentos do blues: a cena e(m) personagens na cidade de Fortaleza 1988-1998. 2012. Monografia (Graduação em História), Universidade Estadual do Ceará, Fortaleza, 2012.

BARBOSA, Leopoldo de Macedo. Fique escutando que eu vou aqui cantando meu Blues Pai D’Égua: a produção "blues" de Fortaleza entre relações e encontros 1989-1999. 2018. Dissertação (Mestrado acadêmico em História), Universidade Estadual do Ceará, Fortaleza, 2018.

CERTEAU, Michel de. A invenção do cotidiano: Artes de fazer 1. Petrópolis-RJ: Editora Vozes, 1998.

CORREA, M. G. O conceito de gênero musical no repertório e nas áreas de antropologia, comunicação, etnomusicologia e musicologia. ARJ - Art Research Journal / Revista de Pesquisa em Artes, v. 5, n. 2, 5 jun. 2019, p. 1-18.

FONSECA, Rafael Sânzio Nunes. A cena musical indie em Belo Horizonte: novos padrões de carreira no interior de uma cena local. Dissertação (Mestrado em Ciências sociais), Universidade Federal de Minas Gerais, Belo Horizonte, 2011.

GARSON, Marcelo. Bourdieu e as cenas musicais - limites e barreiras. In: XXXII Congresso Brasileiro de Ciências da Comunicação, 2009, Curitiba - PR. Anais eletrônicos..., Curitiba: Universidade Positivo - PR, 2009.

JANOTTI JR., Jeder. War for Territory: cenas musicais, experiência estética e uma canção heavy metal. E-compós, Brasília, v. 17, n. 2, mai. / ago. 2014, p. 1-17.

MUGGIATI, Roberto. Blues - da lama à fama. Rio de Janeiro: Ed. 34, 1995.

RODRIGUES, Venize Nazaré Ramos. Espaço Urbano e Memória do Trabalho: Belém nos Meados do XX. In: SOUZA, Antônio Clarindo Barbosa de (ORG.). Populares na Cidade: Vivências de Trabalho e de Lazer. João Pessoa. Ideia, 2011, p. 13-37.

SÁ, Simone Pereira de. Will Straw: cenas musicais, sensibilidades, afetos e cidades. In: JANOTTI JR., Jeder; GOMES, Itania Maria Mota (ORGS.). Comunicação e Estudos culturais. Salvador: EDUFBA, 2011, p. 147-163.

STRAW, Will. Cenas Culturais e as Consequencias Imprevistas das Politicas Publicas. In: JANOTTI JR., Jéder; SÁ, Simone Pereira (ORGS.). Comunicações e territorialidades: Cenas Musicais. Guararema: Anadarco, 2013, p. 13-24.

STRAW, Will. "Systems of articulation, logics of change: Scenes and communitiesin popular music”.Cultural Studies, v. 5, n. 3, 1991, p. 361-375. 